\title{
GENETICAL AND ENVIRONMENTAL INTERACTIONS AFFECTING RESISTANCE IN RADISH TO CABBAGE ROOT FLY
}

\author{
P. CRISP, A. G. JOHNSON, P. R. ELLIS and J. A. HARDMAN \\ National Vegetable Research Station, Wellesbourne, Warwick
}

Received 11.x.76

\begin{abstract}
Summary
Laboratory and field experiments on egg-laying preferences of cabbage root fly revealed differences between types of radish varieties which were expressed consistently in all experimental environments. First generation progenies showed responses to low selection pressure but expression of this response was considerably affected by the environment, even when environmental differences consisted only of replications of the same experiment. It is postulated that a genetic factor in the plant affects ontogeny-dependent preference by the fly, that the expression of this factor is itself highly affected by the environment, and that this may be maintained in radish as an adaptive polymorphism.
\end{abstract}

\section{Introduction}

ElLIS et al. (1976) reported experiments on breeding for resistance to cabbage root fly (Delia brassicae (Hoffmann segg in Wiedemann)) in radish (Raphanus sativus L.) by means of selecting plants on the basis of egg-laying preference by the pest. They used a test chamber housed in controlled laboratory conditions (Ellis and Hardman, 1975) in which they both selected and tested the progenies from four varieties. A response to selection for both increased and decreased preference by the fly was demonstrated in first generation progenies. However, the direction and magnitude of this response was inconsistent between replicated experiments. They pointed out that the inconsistencies could be due to interactions between host, pest and factors which were not controlled in the tests. In particular, it was suggested that the total load of eggs and the physiological ages of the plants may have influenced the results. This paper explores these and other factors and includes a comparison of genotypes in the laboratory and the field.

\section{MAterials AND MEthods}

Full descriptions of the plant material, the test procedures and the laboratory experimental designs have already been given (Ellis and Hardman, 1975; Ellis et al., 1976). The present account also includes data from a field experiment: pot sown plants were transplanted to the field at the four-true-leaf stage, on 4th September 1971 at $0.3 \mathrm{~m}^{2}$ spacing with full randomisation, to coincide with the autumn population of the adult fly. Table 1 lists the main features of the six experiments under consideration.

In all cases numbers of eggs per plant were analysed as $\log _{e}\left(x+\frac{3}{8}\right)$; various other transformations (e.g. $x^{0.3}$ as used by Finch et al., 1975) had been found either to have no effect on the analyses, or to increase error 
terms or inexplicable interactions. Analysis of variance models and expectations of mean squares were derived by the method of Scheffé (1959). In the first experiment (EB6 in table 1), where nine varieties were compared, all variables were treated as random. In all other experiments varieties numbered only 2 or 4 , and because our interest was specifically in these varieties they were considered as fixed variables. All other treatments were taken as random including the directional selections, for as Ellis et al. (1976) had shown, this criterion was not always predictive in its effects. Where several genotypes were included in an experiment, data were also analysed

TABLE 1

Details of experiments concerned with egg-laying preference of cabbage root fy in radish

\begin{tabular}{|c|c|c|c|}
\hline Experiment & Site & $\begin{array}{l}\text { Time course of } \\
\text { recording the } \\
\text { experiment (days) }\end{array}$ & Genotypes \\
\hline EB6 & Laboratory & 5 & 9 commercial varieties \\
\hline EB17 & Laboratory & 5 & $\begin{array}{l}2 \text { varieties } \times 2 \text { lots each of high and low } \\
\text { preference selections }=8 \text { genotypes }\end{array}$ \\
\hline EB16 & Laboratory & 5 & $\begin{array}{l}4 \text { varieties } \times 2 \text { lots each of high and low } \\
\text { preference selections }=16 \text { genotypes }\end{array}$ \\
\hline EB26 & Laboratory & 5 & As EB16 \\
\hline EB27 & Field & 25 & As EB16 \\
\hline EB31 & Laboratory & 6 & $\begin{array}{l}\text { High and low selections from one variety, } \\
\text { kept separate }\end{array}$ \\
\hline
\end{tabular}

as regressions of mean eggs per genotype on (1) the mean egg number of all genotypes at each exposure to the fly within an experiment, that is, on the environmental mean; and on (2) the $\log _{e}$ days after recording commenced. The slopes from the first of these regressions $\left(b_{1}\right)$ gave a measure of the change in the number of eggs laid on a genotype relative to the change in the number of eggs laid on the whole population of genotypes. It is referred to as the egg density-dependent parameter. The other variables $\left(b_{2}\right)$ measured the change in attractiveness of the genotype during its ontogeny in the course of the experiment and is referred to as the age-dependent parameter.

If differences in the relative ontogenies of genotypes occurred, then this single factor could have led to changes in both parameters. Because of this potential correlation they were estimated by multiple rather than linear regression, and were then used separately. In many experiments the regression analysis depleted the degrees of freedom to zero, and these two parameters were used, without significance tests, as covariates to adjust mean egg numbers.

\section{Results}

Tables of means from some of these experiments have already been published (Ellis et al., 1976); detailed results are available from the authors on request. We present the results here as components of variance.

(i) Test of varieties in the laboratory (experiment EB6)

Nine varieties were exposed as two replicate batches to a population of the fly in the laboratory test chamber on three successive occasions over a 
5-day period. There were 10 plants of each variety in each replicate batch.

Table 2 shows that there were large and significant differences in the numbers of eggs laid on different varieties in both replicates, with a small but significant component of the variation attributable to successive exposures, that is to age differences. There was also an appreciable and significant variety $\times$ replicate interaction, which reflected observed differences in the ranking of varieties within each replicate.

TABLE 2

Analyses of variance of cabbage root $f y$ eggs laid on nine radish varieties in the laboratory (experiment EB6)

\begin{tabular}{|c|c|c|c|c|}
\hline \multirow[b]{2}{*}{ Item } & \multirow[b]{2}{*}{ d.f. } & \multicolumn{3}{|c|}{ Variance components (\%) } \\
\hline & & Replicate 1 & Replicate 2 & $\begin{array}{c}\text { Both } \\
\text { replicates }\end{array}$ \\
\hline Variety (V) & 8 & $81 * * *$ & $76 * * *$ & $49 * * *$ \\
\hline Age (A) & 2 & $1 * * *$ & $2 * * *$ & $2 * * *$ \\
\hline Replicate (R) & 1 & - & - & $8 *$ \\
\hline $\mathrm{V} \times \mathrm{A}$ & 16 & 0 & 0 & 2 \\
\hline $\mathrm{V} \times \mathrm{R}$ & 8 & - & - & $19 * * *$ \\
\hline Error & 243 & 18 & 21 & - \\
\hline & 531 & - & - & 21 \\
\hline
\end{tabular}

Analysis of the mean data (table 3 ) showed a reduction in the variety $x$ replicate interaction due to the age-dependent covariate $\left(b_{2}\right)$; the egg density-dependent coveriate $\left(b_{1}\right)$ had no effect. This indicated that some of the inconsistencies between the replicates in the attractiveness of the varieties were explicable in terms of different linear age-dependent responses of the varieties in the two replicates. Hence, although the variety component remained constant, and suggested that true genetic differences existed, ontogenetic factors appeared to have confounded these varietal differences between replicated experiments.

TABLE 3

Adjustment of mean egg numbers per plant of analysis given in table 2 by egg density $\left(\mathrm{b}_{1}\right)$ and age $\left(\mathrm{b}_{2}\right)$ dependent variates (experiment $\left.E B 6\right)$

\begin{tabular}{|c|c|c|c|c|c|}
\hline & & & ce co & nts & \\
\hline & & & & iates & \\
\hline Item & d.f. & $\begin{array}{c}\text { Mean } \\
\text { eggs/plant }\end{array}$ & $\mathrm{b}_{1}$ & $b_{2}$ & Both \\
\hline Variety (V) & 8 & $27 *$ & $27 *$ & $31 *$ & $31 *$ \\
\hline Replicate (R) & 1 & 6 & 6 & 4 & 4 \\
\hline $\mathrm{V} \times \mathrm{R}$ & 8 & $12 *$ & $12 *$ & $8 *$ & $8 *$ \\
\hline Error & 162 & 56 & - & - & - \\
\hline & 161 & - & 55 & 58 & - \\
\hline & 160 & - & - & - & 58 \\
\hline
\end{tabular}

The two replicate batches had been raised together, with single plant randomisation within but not between them. A slight difference in location of the two replicates within the glasshouse had been sufficient to result in a barely appreciable etiolation of one replicate. This, perhaps in concert 
with other unquantified micro-environmental factors was associated with a significant difference in the overall numbers of eggs laid on the two replicates (table 2), despite both replicates being exposed alternately to the same fly population. One replicate had a geometric mean of 37.9 eggs per plant, the other had $24 \cdot 9$.

This overall difference could not be accounted for by a progressive change in the numbers of eggs laid by the fly populations, and this suggested that the overall attractiveness of the two replicates had differed. In addition, this replicate difference was manifested in relative differences in the numbers of eggs laid on each variety and this was not a function of the overall differences in the numbers of eggs laid in each replicate, as the egg densitydependent covariate had no effect on the mean egg analysis.

This result deserves emphasis: very minor environmental differences resulted in appreciable differences in the overall and component attractiveness of a population of genotypes, and this appeared at least in part to be an effect of environment on the relative ontogenies of genotypes.

\section{(ii) The effects of selection}

In nine varieties about 30 per cent, respectively, of plants most or least preferred by the fly in the laboratory had been selected, to give first generation progenies (Ellis et al., 1976). Some of these were tested in the laboratory both in mixtures and where no alternative genotypes were available, and in the field.

\section{(iia) Tests in the laboratory (experiments EB17, EB16 and EB26)}

The first of these experiments (EB17) consisted of 11 plants each of high and low selections made from two random samples each of two varieties (Tip Top and Sparkler) - a total of eight genotypes. They were exposed to the flies in two replicates on three occasions over 5 days. As with the previous experiment, there was a significant replicate effect, and a significant genotype $\times$ replicate interaction due to the random selection component (table 4). Genotypic differences were entirely due to the effects of selection,

TABLE 4

Analysis of variance of cabbage root fly eggs laid on selections from two varieties, in the laboratory (experiment EB17)

Item

$\begin{array}{ll}\text { Genotype } & \left\{\begin{array}{l}\text { Variety }(\mathrm{V}) \\ \text { Random selection (S) } \\ \text { Preferential selection (P) }\end{array}\right. \\ \text { Environment } & \left\{\begin{array}{l}\text { Replicate (R) } \\ \text { Age (A) }\end{array}\right. \\ \text { Genotype } \times \text { environment }\left\{\begin{array}{l}\text { VR } \\ \text { SR } \\ \text { PR } \\ \text { VA } \\ \text { SA } \\ \text { PA }\end{array}\right.\end{array}$

Error

$\begin{array}{rc}\text { d.f. } & \text { Variance component }(\%) \\ 1 & 0 \\ 2 & 6 \\ 4 & 7^{* * *} \\ 1 & 5^{* *} \\ 4 & 0 \\ 1 & 0 \\ 2 & 6^{* *} \\ 4 & 1 \\ 4 & 0 \\ 8 & 0 \\ 16 & 0 \\ 479 & 76\end{array}$


and of these preferential selection had a significant effect. Adjustment of mean egg numbers by the density-dependent covariate $\left(b_{1}\right)$ again had little effect (table 5). However, the age-dependent covariate $\left(b_{2}\right)$, while not affecting the overall genotypic component, redistributed the effects of selection by reducing the effect of preferential selection to a non-significant level, and also redistributed the genotype $\times$ replicate interaction into smaller components. These results suggested that the effect of selection had been to change the relative age-dependent attractiveness within the population, and this character was changed in an inexplicable manner by the environmental (i.e. replicate) effects on different genotypes.

A further two experiments (EB16 and EB26) were identically designed and consisted of five plants each of high and low selections from two random

\section{TABLE 5}

Adjustment of mean egg numbers per plant of analysis given in table 4 by egg density $\left(\mathrm{b}_{1}\right)$ and age $\left(\mathrm{b}_{2}\right)$ dependent variates (experiment EB17)

\begin{tabular}{|c|c|c|c|c|c|}
\hline & & & ance $c c$ & ments $(c$ & \\
\hline & & & & Covariat & \\
\hline Item & d.f. & egg/plant & $b_{1}$ & $b_{2}$ & Both \\
\hline (Variety $(\mathrm{V})$ & 1 & 0 & 0 & 2 & 0 \\
\hline Genotype $\{$ Random selection $(\mathrm{S})$ & 2 & 7 & 7 & $11 * * *$ & 12 \\
\hline Preferential selection & 4 & $6^{*}$ & $7 *$ & 3 & $6 *$ \\
\hline Environment Replicate (R) & 1 & $6 * *$ & $7 * *$ & $8 * * *$ & $8 * * *$ \\
\hline CVR & 1 & 0 & 0 & 1 & 2 \\
\hline Genotype $\times$ environment $\{\mathrm{SR}$ & 2 & 6 & 5 & 2 & 2 \\
\hline \begin{tabular}{l|l} 
PR \\
\end{tabular} & 4 & 0 & 0 & 1 & 0 \\
\hline Error & 160 & 74 & - & - & - \\
\hline & 159 & - & 74 & 72 & - \\
\hline & 158 & - & - & - & 72 \\
\hline
\end{tabular}

samples each of four varieties (Tip Top, Sparkler, French Breakfast and Cherry Belle), giving a total of 16 genotypes, which were again exposed to the flies in two replicates on three occasions over 5 days. Each experiment revealed significant varietal differences and responses to preferential selection (table 6). However, they were not consistent in their genotype $\times$ replicate interactions, and the covariates did little to affect these analyses although in both experiments the covariates slightly reduced the effects of preferential selection (table 7). When both experiments were analysed together, very little interaction was apparent between selections and experiments (table 8), indicating that the effects of selection had been consistently expressed; and; again, use of the covariates had no effect. A significant variety $\times$ experiment interaction was also not affected by the covariates.

\section{(iib) Tests in the field (experiment EB27) and comparison with laboratory tests}

The same genotypes used in experiments EB16 and EB26 in the laboratory were assessed in the field in experiment EB27. There was no block replication of the experiment, which contained five plants of each of the 16 genotypes. Eggs laid over six intervals of 3 to 7 days were counted.

A significant difference was shown between varieties, but a slight effect due to preferential selection was not significant (table 9). The time course 
of this experiment (25 days) made improbable any linearity in the fly's response to the plants' ontogeny, and no genotype $\times$ age interactions were revealed by the analysis of variance. Indeed, plotting the data revealed considerable and inconsistent variability in the relative attractiveness of the

TABLE 6

Analyses of variance of cabbage root fly eggs laid on the same selections from four varieties in two experiments in the laboratory

\begin{tabular}{|c|c|c|c|c|}
\hline & & & Variance $c$ & ponent $(\%)$ \\
\hline Item & & d.f. & Experiment EB16 & Experiment EB26 \\
\hline Genotype $\left\{\begin{array}{l}\text { Variety }(\mathrm{V}) \\
\text { Random selec } \\
\text { Preferential se }\end{array}\right.$ & $\begin{array}{l}\text { tion }(\mathrm{S}) \\
\text { lection }(\mathrm{P})\end{array}$ & $\begin{array}{l}3 \\
4 \\
8\end{array}$ & $\begin{array}{l}9 * \\
4 \\
10 * * *\end{array}$ & $\begin{array}{l}12 * \\
0 \\
11 * * *\end{array}$ \\
\hline Environment $\left\{\begin{array}{l}\text { Replicate } \\
\text { Age (A) }\end{array}\right.$ & (R) & $\begin{array}{l}1 \\
4\end{array}$ & $\begin{array}{l}0 \\
4\end{array}$ & $\begin{array}{l}0 \\
0\end{array}$ \\
\hline Genotype $\times$ environment \{ & $\begin{array}{l}\text { VR } \\
\text { SR } \\
\text { PR } \\
\text { VA } \\
\text { SA } \\
\text { PA }\end{array}$ & $\begin{array}{r}3 \\
4 \\
8 \\
12 \\
16 \\
32\end{array}$ & $\begin{array}{l}1^{*} \\
0 \\
2 \\
0 \\
0 \\
0\end{array}$ & $\begin{array}{l}0 \\
9 * * \\
0 \\
0 \\
0 \\
0\end{array}$ \\
\hline Error & & 384 & 69 & 68 \\
\hline
\end{tabular}

TABLE 7

Adjustment of mean egg numbers per plant of analyses given in table 6 by egg density $\left(\mathrm{b}_{1}\right)$ and age $\left(\mathrm{b}_{2}\right)$ dependent variates

\section{Item \\ Genotype $\left\{\begin{array}{l}\text { Variety }(\mathrm{V}) \\ \text { Random } \\ \text { selection }(\mathrm{S}) \\ \text { Preferential } \\ \text { selection }(\mathrm{P})\end{array}\right.$}

Environment Replicate (R)

Genotype $\times$ environinent $\left\{\begin{array}{l}\mathrm{VR} \\ \mathrm{SR} \\ \mathrm{PR}\end{array}\right.$ Error

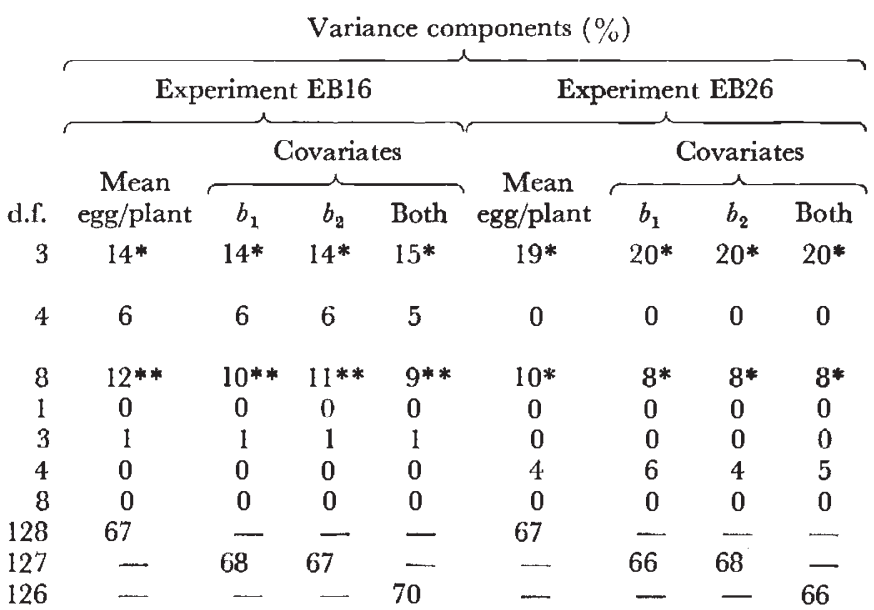

genotypes, with no apparent pattern. Rankings of genotypes at particular dates did not correlate with those within the laboratory experiments of the same genotypes, although varietal means were ranked such that Tip Top and French Breakfast were always less preferred than Cherry Belle and Sparkler in both laboratory and field experiments (table 10). Table 10 also records the ranking found in another field experiment with the same genotypes which had such low egg numbers (a mean of $8 \mathrm{eggs} /$ plant over 18 days) that 
TABle 8

Analysis of variance of cabbage root fly eggs laid on selections from four varieties in two laboratory experiments ( $E B 16$ and EB26)

\begin{tabular}{|c|c|c|c|}
\hline \multicolumn{2}{|l|}{ Item } & d.f. & Variance components (\%) \\
\hline \multirow{3}{*}{ Genotype } & Variety $(\mathrm{V})$ & 3 & $4 *$ \\
\hline & Random selection (S) & 4 & 0 \\
\hline & Preferential selection (P) & 8 & $3 * * *$ \\
\hline & 1 & $69 * * *$ \\
\hline & Environment $\{$ Replicate $(\mathrm{R})$ & 2 & 0 \\
\hline \multirow{6}{*}{ Genotype $\times$} & VX & 3 & $2 * *$ \\
\hline & $\mathrm{SX}$ & 4 & 0 \\
\hline & environment & 8 & 1 \\
\hline & cinvisoninteris & 6 & 0 \\
\hline & SR & 8 & 0 \\
\hline & PR & 16 & 0 \\
\hline \multicolumn{2}{|l|}{ Error } & 256 & 21 \\
\hline
\end{tabular}

TABle 9

Analysis of variance of cabbage root fly eggs laid on selections from four varieties in the field (experiment EB27)

Item

Genotype $\left\{\begin{array}{l}\text { Variety (V) } \\ \text { Random selection (S) } \\ \text { Preferential selection (P) }\end{array}\right.$

Environment Age

Genotype $\times$ environment $\left\{\begin{array}{l}\text { VA } \\ \text { SA } \\ \text { PA }\end{array}\right.$

d.f. Variance components $(\%)$

Error

$\begin{array}{rl}3 & 4 * * * \\ 4 & 0 \\ 8 & 1 \\ 5 & 6 * * * \\ 15 & 0 \\ 20 & 0 \\ 40 & 0 \\ 384 & 89\end{array}$

TABLE 10

Geometric mean egg numbers on four radish varieties or their progenies exposed to cabbage root fies in laboratory and field experiments

Variety

Type

\begin{tabular}{|c|c|c|c|c|c|}
\hline \multicolumn{4}{|c|}{ Laboratory } & \multicolumn{2}{|c|}{ Field } \\
\hline EB6 & EB16 & EB26 & EB17 & EB27 & $\begin{array}{c}\mathrm{EB} 27 \\
\text { (repeat) }\end{array}$ \\
\hline $12 \cdot 5$ & $61 \cdot 9$ & $9 \cdot 1$ & - & 10.7 & $1 \cdot 1$ \\
\hline $18 \cdot 0$ & $65 \cdot 5$ & $15 \cdot 0$ & $40 \cdot 9$ & $9 \cdot 9$ & 0.9 \\
\hline $70 \cdot 1$ & $96 \cdot 4$ & $34 \cdot 8$ & - & $20 \cdot 7$ & $1 \cdot 2$ \\
\hline $67 \cdot 1$ & 168.4 & $23 \cdot 5$ & $57 \cdot 1$ & 17.9 & $1 \cdot 7$ \\
\hline
\end{tabular}

Tip Top

French Breakfast

Intermediate Intermediate

Globe

$67 \cdot 1$

$68.4 \quad 23.5$

$17 \cdot 9 \quad 1.7$

sampling error accounted for virtually all of the variation. Additionally, data for these four varieties are included from the experiment with nine varieties (EB6) and for two of these varieties from EB17; again, the same ranking of types was observed.

\section{(iic) Attractiveness of a genotype in the absence of alternative genotypes}

Ellis et al. (1976) reported that a high preference selection from the variety Tip Top had about three times as many eggs laid on it as did a low selection from the same variety when the genotypes were assessed in isolation from each other and other genotypes (experiment EB31). 
Comparison of this performance of the two genotypes with their performance in experiments where alternative genotypes were available to the flies (table 11) indicated that the same kind of difference between these

TABLE 11

Numbers of eggs laid on first generation high and low selections from variety Tip Top in experiments where different numbers of other genotypes were available

$\begin{array}{ccclcc}\begin{array}{c}\text { Geometric mean } \\ \text { number of eggs } \\ \text { laid per plant } \\ \text { over whole } \\ \text { experiment }\end{array} & \begin{array}{c}\text { Duration of } \\ \text { recording } \\ \text { (days) }\end{array} & \begin{array}{l}\text { Location } \\ \text { Experiment }\end{array} & \begin{array}{c}\text { \% eggs laid on } \\ \text { high selection } \\ \text { and significant } \\ \text { difference from } \\ \text { low selection }\end{array} & \begin{array}{c}\text { Number of } \\ \text { other } \\ \text { genotypes in } \\ \text { experiment }\end{array} \\ \text { EB27 } & 61 & 25 & \text { Field } & 33 \text { n.s. } & 14 \\ \text { EB31 } & 21 & 6 & \text { Laboratory } & 75 * * * & 0 \\ \text { EB26 } & 54 & 5 & \text { Laboratory } & 76 * * * & 14 \\ \text { EB17 } & 146 & 5 & \text { Laboratory } & 65 * * * & 2 \\ \text { EB16 } & 270 & 5 & \text { Laboratory } & 60^{*} & 14\end{array}$

lines was manifested in " choice" as in "no choice" conditions. Table 11 also shows that differentiation between the genotypes appeared to decrease at higher egg densities in the laboratory; and that a non-significant differentiation could be made between genotypes on the basis of the field experiment. It is noteworthy, however, that this relationship in the field, although nonsignificant, was opposite to that in the laboratory (fig. 1).

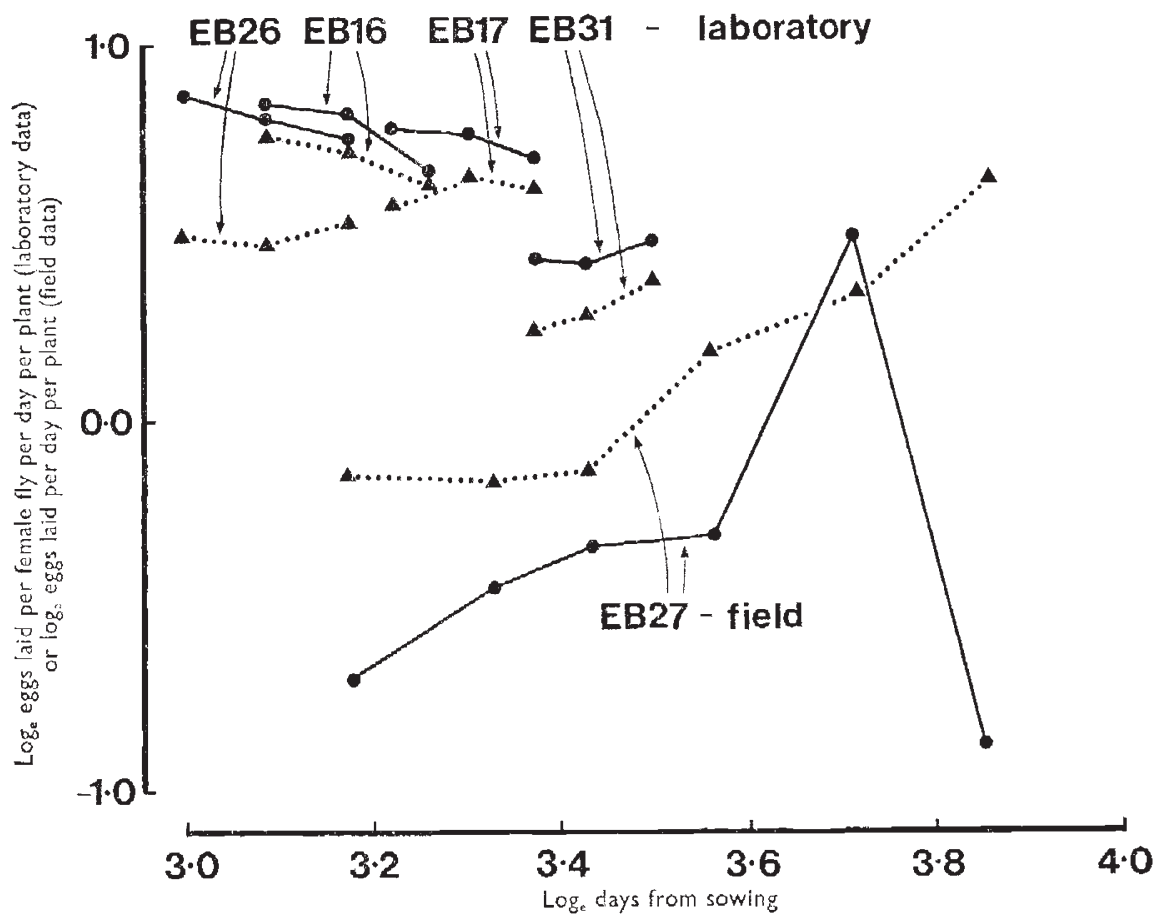

FIG. 1.-Egg numbers laid on two genotypes in four laboratory experiments and one field experiment. The genotypes were selected from cv. Tip Top as being preferred (circles) or less preferred (triangles) by the fly. 


\section{Discussion}

Our results indicated that in short-term experiments (5 or 6 days) genotypic differences could often be accounted for by random or preferential selection having been made from parental varieties; and the results of Ellis et al. (1976) indicated a tendency for the response to selection to be in the expected direction.

The longer-term field experiment (25 days) revealed no such response to selection. However, the broad differences between types of varieties in this experiment were the same as in the short-term experiments. That is, varietal groups differed in attractiveness during long periods of the species' ontogeny, and genetic variability existed within varieties for attractiveness during small parts of this ontogenetic span.

The consistency with which the "globe" type of radish was preferred to the "intermediate" type indicated that the expression of this kind of difference was probably not fundamentally affected by the environment. However, the considerable interactions between selections within varieties and replicates of some experiments indicated that the expression of this genetic component was subject to environmental factors. This conclusion is perhaps supported by comparison of two genotypes of Tip Top (fig. 1), which although consistent in their ranking in laboratory experiments, were reversed (although non-significantly) in attractiveness in the field.

The use of the changing attractiveness of the plants as a covariate tended to reduce these genotype $\times$ environment interactions without affecting varietal differences. This suggested that selection had affected relative ontogeny-dependent attractiveness within varietal populations.

Use of the covariate based on the mean number of eggs did not change the components of variation in the analyses, indicating that the expression of phenotypic differences was independent of the total number of eggs laid. Indeed, the results of the "no choice" experiment (EB31) suggested that the plant phenotype available to the fly directly affected the number of eggs laid; and the experiment with nine varieties (EB6) showed that differences in the overall number of eggs laid did not affect the discrimination within the plant population. In this context, the results of the two Tip Top genotypes in various genotypic mixtures (table 11) were of interest, for the laboratory data indicated that irrespective of alternative genotypes, the discrimination between these two genotypes apparently decreased as egg numbers increased. However, consideration of these data on a log scale, taking into account the numbers of female flies, revealed no such distinction (fig. 1) and suggested that the results given in table 11 were a statistical anomaly.

These conclusions can be accommodated within a general hypothesis that the sum of the component phenotypes of a plant population determines the number of eggs laid by a specific fly population. Additionally, discrimination within the plant population may operate not in a competitive manner between plant phenotypes, but in a consistent and as yet unknown manner dependent upon both gross varietal differences and environmental effects on the relative ontogenies of the genotypes.

Very low directional selection pressure (30 per cent), or indeed random selection of small numbers (usually 10) of plants from varietal populations led to quite substantial genetic shifts in ontogeny-dependent attractiveness as 
detected in one experiment (EB17). This raises the question as to why this variability should exist within different, isolated, genetic stocks which, since the general advent of agricultural insecticides two decades ago must, when being developed or reseeded, have been under very little selection pressure from the fly. Because of the attractiveness of most cruciferous species for the fly (Finch and Ackley, 1977), and our failure to find non-preference resistance in a wide range of Brassica oleracea (unpublished data), we conclude that most and perhaps all cruciferous species, including radish, may inevitably be attacked if flies have access to them. It is, of course, possible that other parameters of survival - say, susceptibility to another pest - render the individuals which are less preferred by the cabbage root fly less likely to pass on this resistance; thus maintaining a polymorphic balance. However, perhaps the most effective manner in which a crucifer could have adapted to accommodate the fly would be to maintain a polymorphism such that some plants were less preferred in any given population and survived attack, and that the genetic factors affecting this preference were expressed in grossly different ways in slightly different environmental conditions. Thus, selection pressure by the fly might favour certain genotypes in some microenvironments, and different genotypes in adjacent micro-environments, and the outbreeding nature of radish would then ensure recombination and no net gene loss at each generation. That is, an age-dependent genotype $\times$ environment interaction such as that which we detected might have become fixed in the radish population. The ease with which we effected a genetic shift suggests that if this hypothesis is correct, the genetic component of the system is maintained by a few rather than many heritable factors.

Hence, breeding for resistance to the fly might be effective if directed towards two ends; either to exploit the gross varietal type differences; or to fix part of the postulated polymorphism, perhaps integrating this with the application of insecticide at a critical stage during the plant's ontogeny.

Acknowledgments.-We extend our gratitude to Kathleen Phelps for assistance with the computing, to G. H. Freeman and M. J. Lawrence for helpful discussion, and to Elaine Roberts, Elaine Sanders, Barbara G. Symons and Valerie I. Bourne for technical assistance.

\section{REFERENCES}

ELLIS, P. R., AND HARDMAN, J. A. 1975. Laboratory methods for studying non-preference resistance to cabbage root fly in cruciferous crops. Ann. Appl. Biol., 79, 253-264.

ELLIS, P. R., HARDMAN, J. A., GRISP, P., AND JOHNSON, A. G. 1976 . Non-preference resistance to cabbage root fly in radish. Ann. Appl. Biol., 84, 81-89.

FINGH, s., SKINNER, G., AND FREEMAN, G. H. 1975. The distribution and analysis of cabbage root fly egg populations. Ann. Appl. Biol., 78, 1-18.

FINCH, s., AND ACKLEY, c. M. 1977. Cultivated and wild host plants supporting populations of the cabbage root fly. Ann. Appl. Biol, 85, 13-22.

sCHeffé, H. 1959. The Analysis of Variance. John Wiley, New York. 